\title{
Augusto Teixeira de Freitas - El Protojurista del Mercosur
}

\section{Florisbal de Souza Del'Olmo'}

Cuando se habla en Mercosur nada mejor que tejer consideraciones sobre la figura paradigmática de Augusto Teixeira de Freitas, nacido en Cachoeira, Estado de Bahia, el 19 de agosto de 1816, y fallecido en Niterói, Estado de Rio de Janeiro, el 12 de diciembre de 1883.

Esto porque el insigne jurista brasileño tiene su nombre ligado a la codificación del Derecho Civil en los cuatro paises que hoy constituyen el futuroso bloque económico regional del Cono Sur de América, que ha completado diez años de su creación.

Teixeira de Freitas hizo su curso de Ciencias Juridicas y Sociales en las dos más antiguas Facultades de Detecho de Brasil, en São Paulo y en Olinda, donde se graduó en 1837, regresando a Bahia para ejercer la abogacía y la magistratura. Luego, no obstante, se transfería para la ciudad de Rio de Janeiro, donde fue uno de los fundadores del Instituto de los Abogados Brasileños, viniendo a ejercer la presidencia del mismo en 1857.

Disciplinado, inteligente, estudioso, humanista y dotado de un profundo sentimiento de justicia, Freitas dejaría una obra que inmortalizó su nombre, honró su patria y ennobleció su época, sirviendo aún de punto de convergencia en la legislación civil entre los pueblos hermanos que, un siglo después de su muerte, se integrarían en el Mercado Común del Sur, el Mercosur.

\footnotetext{
${ }^{1}$ Maestro en Derecho por la UFSC, Florianópois, SC. Profesor de Dexecho Internacional Privado y Derecho Internacional Público, en la Universidad Regional Integrada del Alto Uruguay y de las Misiones, URI, campus de Santo Ârgelo, RS, y en el Instituto de Enseñanza Superior de Santo Ângelo, IESA. Es profesor convidado del Curso de Especiatização Lato Sensu, de la Faculdade de Direito da Universidade Federal do Amazonas, UA, Manaus, AM, e del curso de especialización El Nuevo Derecho Internacional, de la Facultad de Derecho de la UFRGS, Porto Alegre, RS. Autor de Direito Intemacional Privado - Abordagens Fundamentais, Legislação, Jurisprudência, 2. ed., 2000, O Mercosul e a Nacionalidade: Estudo a Luz do Direito Internacional, 2001, y Curso de Direito Internacional Público, 2002, todos por la Editoxa Forense, Rio de Janeiro, R., Brasil.
} 
En 1857 fue publicada en Rio de Janeiro la "Consolidação das Leis Civis", obra en la cual Teixeira de Freitas, poco más de dos años de trabajo después, ordenó, clasificó y actualizó el derecho legislado, desordenado, confuso y impreciso, entonces vigente en Brasil. Se trataba de leyes, decretos, asientos, albarás, resoluciones, reglamentos y además preceptos juridicos, desde las ordenaciones portuguesas, muchas de ellas ya revocadas en la tierra lusa, a las normas juŕdicas brasileñas de las tres primeras décadas después de la Independencia. Haroldo Valladão consideró tal obra como la Carta Magna de la independencia jurídica brasileña.

El respecto y la notoriedad granjeados con el incomparable trabajo de consolidación hicieron con que 'Teixeira de Freitas fuese incumbido por el gobietno imperial, en 1859, para redactar un código civil, que se sabía adelantado y avanzado. Él presentó el resultado de sus estudios, en fascículos, después reunidos en dos volúmenes con 4908 artículos, bajo el título "Código Civil - Esboço", en 1860 . Se trata de un estudio cuidadoso que tiene merecido desde entonces los comentatios más lisonjeros de juristas del mundo todo.

Un nuevo entendimiento, todavía, animó Teixeira de Freitas, convencido de que sería más conveniente para el ordenamiento jurídico brasileño un Código de Derecho Privado, un Código General, en el cual estarian inseridas la legislación civil y comercial, las normas delimitadoras de las obligaciones, definiciones y reglas sobre publicación, interpretación y aplicación de las leyes. La búsqueda incesante de la petfección y el gigantismo de la tarea ya lo habían obligado a necesitar de más tiempo, prorrogado hasta 1864. Pero, lamentablemente, el gobierno no fue receptivo a las nuevas ideas del jurista y el contrato fue rescindido, interrumpiéndose el trabajo con el código aún incompleto.

Como se sabe, el Brasil vería postetgado el surgimiento de su primero código civil por más de medio siglo. Solamente en 1917 entratra en vigencia el Código Civil brasileño, que tuvo como principal autor Clóvis Beviláqua, pero en el cual muchas ideas de Teixeira de Freitas fueran incorporadas.

Quiso el destino, todavía, que el inolvidable proyecto del jurista brasileño fuese de enorme validad en la elaboración del Código Civil de Argentina, país donde él es citado y sus textos estudiados. En ese monumental repositorio de la legislación civil continental considerado por Ramón Silva Alonso como un Código Civil avanzado, "uno de los mejores de América en su tiempo" - coordinado por Dalmacio Vélez Sarsfield, el Esbozo sirvió de espina dorsal en un gran número de institutos, para los cuales fueran utilizados los attículos redactados por Teixeira de Freitas, y hasta sus notas explicativas.

${ }^{2}$ SILVA ALONSO, Ramón. Derecho internacional privado, p. $88.5^{2}$ ed. Asunción: Intercontinental, 1999. 
Exaltando la importancia de la obra de Teixeira de Freitas en la codificación civil argentina, muchos juristas de ese país tienen hecho generosas y simpaticas referencias a él. Así, Martinez Paz, citado por Valladão, afirmó: "La consolidación es el monumento más alto del pensamiento juridico americano; las codificaciones y los trabajos de exégesis y comentario, así como los escasos tratados de dogmática ni en punto a erudición, ni en doctrina han alcanzado ese sello de originalidad, de sentido personal y de profundidad que caracteriza a la Consolidación de las leyes civiles"."

Aún, según Valladão, Abel Chaneton, ilustre historiador argentino, se expresó con estas palabras sobre Teixeira de Freitas: "La Consolidación lo elevó de golpe al rango de 'el más importante jurisconsulto de América".4 Y René David, profesor de la Facultad de Derecho de París: "Se pasaron casi cien años de la publicación de la Consolidación de las leyes civiles de Teixeira de Freitas; ella conserva, todavía, no obstanre toda la evolución del Derecho ocurrida desde entonces, grande validad y continúa siendo, sin duda, la obra juridica más original y más perfecta de su tiempo producida en Brasil y en toda América Latina".

Otra exaltación al jurista de la Consolidación, ya citada, es la afjmación del argentino Luis Varela: "Preparó el sabio jurisconsulto Doctor Teixeira de Freitas, sin duda alguna, uno de los monumentos más inperecedores que la intelectualidad sudamericana ha levantado a la ciencia jurídica moderna".

Como se afirmó, la obra de Freitas se explayó en los cuatro Estados que componen hoy el Mercosur. Así, el Código Civil del Paraguay, adoptado en 1876, el primero de la historia jurídica guarani, tuvo incorporado el ingenio del insigne brasileño. Como se sabe, ese Estatuto fue una adaptación del Código argentino. Y los grandes juristas paraguayos, del pasado y actuales, tienen enfatizado la contribución del genial jurisconsulto brasileño, como Luis de Gasperi, Raul Sapena Pastor y Ramón Silva Alonso.

\footnotetext{
"VALLADÃO, Haroldo. Direito internacional privado, v, I. p. 169. $4^{\mathrm{a}}$ ed. Rio de Janeiro: Freitas Bastos, 1974.

4 VALLAD $\Lambda O, H$. Idem, ibidem.

${ }^{5}$ VALLADÃO, H. Ydem, ibidem. En el original: "Près de cent ans sont passé depuis la date oí la Consolidation des lois civiles de TEIXEIRA DE FREITAS a été publiée; elle conserve encore, malgré tous les déxoloppenents du Droit intervenus depuis lors une grande valeur et reste sans doute l'oeuvre juridique la plus originale et la plus parfaite à la fois que ait été produite au Brésil et dans toute l'Amérique Latine".

"DELOLMO, Florisbal de Souza. Direito internacional privado: abordagem fundamental, legislação, jurisprudência, p. 11. Rio de Janeiro: Forense, 1999.
} 
El primeto de eses autores, en carta a Haroldo Valladão, afirmó ser Teixeira de Freitas "el único jurista americano que puede alternar en la historia con Savigny y los padres de la codificación germana"?

Ramón Silva Alonso, al comentar el movimiento internacional por la codificación ocurrido en el siglo XIX, afirma: "En la segunda mitad de ese mismo siglo, él llega a Amética. Por ese tiempo surgen en el nuevo continente figuras ejemplares en el mundo jurídico como no han vuelto a aparecer. (...) Augusto Teixeira de Freitas, que escribe para el Brasil, en 1860, el Esbozo, aún hoy no suficientemente valorado ni estudiado". 8

Aún el insigne internacionalista guaraní, Decano de la Facultad de Derecho de la Universidad Nacional de Asunción, escribió: "Coincido con Ud. en que Teixeira de Freitas es sin duda una de las mayores glotias del detecho de su tiempo en América. También creo que Freitas no ha sido aún sufícientemente estudiado ni valorado en el propio Brasil, considerando el tiempo en que le tocó vivir. Salvo la Argentina y quizás el Paraguay, no es suficientemente conocido en el Continente, teniendo en cuenta la grandeza de su figura". " Muy oportunas y sensatas las observaciones del erudito maestro paraguayo, él propio un gran entusiasta de la obra de Teixeira de Freiras.

$\mathrm{Al}$ fin, la codificación civil uruguaya no se ha quedado inmune a la influencia benévola de los estudios de Teixeira de Freitas. El Código Civil de la República Oriental del Uruguay acogió en su Proyecto, de autoría de Tristán Narvaja, postulados del genial jurista brasileño, teniendo el maestro oriental confesado, según Haroldo Valladão, "haberse servido entre los antecedentes para su trabajo del 'Proyecto del Señor Freitas (inconcluso aún), el rrabajo más notable de codificación por su extensión y por el estudio y meditación que revela". ${ }^{10}$ Doctor Narvaja cognominó, en esa ocasión, Teixeira de Freitas de "el Savigny americano". Partiendo $\tan$ fidedigno juicio de autoridad de ese nivel, se entiende el respecto que el inolvidable brasilcño ha merecido en Uruguay.

Lamentablemente en Brasil a erudición de los estudios y la dimensión de la obra de Teixeira de Freitas aún no tuvieron el reconocimiento merecido. Se prueba al recordar que la primera biografía del insigne jurista solamente surgiría casi un cuarto de siglo después de su fallecimiento, ya en 1905, de autoría del Pro fesor Manuel Álvaro Sá Viana.

Además de tardío, ese reconocimiento no ha sido compatible con la dimensión del inolvidable jurisconsulto. Y fue Haroldo Valladão, tantas veces mencionado en este breve

\footnotetext{
' VALLADÃO, H. Op. cit., p. 171-172.

SILVA ALONSO, R. Op. cit., p. 88.

9 SILVA ALONSO, R. Carta de 20 de julio de 1999.
} 
estudio, incuestionablemente, el paladino brasileño en la reverencia al gigantesco perfil de uno de los mayores científicos del Derecho que el país ya conoció. En discurso proferido en el Instituto de los Abogados Brasileños, hace cuarenta años, exactamente cuando recibia la Medalha Teixeira de Freitas, identificando el codificador como el jurista puro, asílo definió Vâlladão: "Abogado, codificador, autor de obras jurídicas, nunca ejerció cargo o función pública, desconoció, completamente, la política, no frecuentó la sociedad; retraído, modesto, vivió vida modelar dedicada al culto del derecho y al amor a la familia, en la meditación con sus libros, en el hogar entre la esposa y los hijos"."

Siendo Teixeira de Freitas un hombre profundamente humanista, nunca es demás mencionat un pasaje de su estudio, ya enfatizada por Valladão en el histórico discurso: "Cumple advertir que no hay un solo lugar de nuestro texto, donde se trate de esclavos. Tenemos, es verdad, la esclavitud entre nosotros; pero, si ese mal es una excepción que lamentamos, y que ya está condenado a extinguirse en una época más o menos remota, hagamos también una excepción, un capítulo desglosado, en la reforma de nuestras leyes civiles, no las maculemos con disposiciones vergonzosas, que no pueden servir para la posteridad; se quede el estado de libertad - sin su correctivo odioso. Las leyes concernientes a la esclavitud (que no son muchas) serán, pues, clasificadas a la parte, y formarán el nuestro Código Negro"." 2

La llaga del servilismo del hombre africano, nunca es despiciendo tecordar, en el Cono Sur de América fue casi una exclusividad brasileña. Solamente a finales del siglo XIX, por la Ley Áurea, firmada por la Princesa Isabel, el 13 de mayo de 1888, sería definitivamente proscrita del ordenamiento jurídico del Brasil la esclavitud. Ese instituto abominable prácticamente inexistió en Argentina, donde desde 1813 no se registran casos, así como en Uruguay y en Paraguay, banidos jurídicamente aún en mediados del mismo siglo.

El avanzado código proyectado por Freitas, como visto, se integró fácilmente en el pensamiento jurídico de los pueblos hispanoamericanos que hoy constituyen el Metcosur, hasta porque tepleto de un saludable espíritu libertatio y agregador. Tuviese el jurista bahiano conseguido realizat su sueño de un código general, con razón se cree que tendría sus estudios agasajados, hasta con más énfasis, en la misma área geográfica.

Se subraye que en 1942 Italia promulgó su acrual Código Civil, versando sobre rodos los asuntos de derecho civil, comercial, industrial y laboral, con que fuetan revocados los códigos y leyes que ahí disciplinaban esas materias. Coincidentemente, el mismo año, se

"VALLADÃO, H. Teixeira de Freitas, jurista excelso do Brasil, da América, do Mundo, p. 423. In: Revista Forense, n"188. Rio de Janeiro, 1960.

$"$ VALLADÄO, H. Iden, p. 417.

12 VALLADÃO, H. Idem, 419. 
integtaba al ordenamiento jurídico brasileño la Ley de Introducción al Código Civil, en la cual el punto de conexión, hasta entonces la nacionalidad, era sustituido por el domicilio, que Teixeira de Freitas defendiera en su propuesta. Como se verifica, pasado más de un siglo, los postulados preconizados para la ciencia del Derecho por el gran jurista empiczan a tornarse ley en los más avanzados ordenamientos jurídicos del mundo.

El Paraguay, en 1987, pasó a contar con un nuevo Código Civil, en el cual continúan presentes los postulados de Teixeira de Freitas, así como la influencia del Código de Napoleón y también del mencionado Código Civil italiano. Son, conforme Ramón Silvá Alonso, los tres modelos que inspiraton esa avanzada codificación, debido al estatuto itálico "las normas que unifican la legislación civil y comercial que realizan la fusión de las obligaciones en estas materias, fusión que se incorpora al Derecho paraguayo". ${ }^{13}$

Cuando en el mundo jutídico contemporáneo pasan a ser admitidos principios que Teixeira de Freitas predicó hace más de un siglo, es llegado el momento de no solo exaltar su obra, como, principalmente, buscar en ella los frutos que tiene a ofrecer.

Se registra, con satisfacción, juicios de grandes estudiosos del Derecho en Btasil que reconocen los méritos del jurista de la Consolidación e del Esbozo. Para Pontes de Miranda, Teixeira de Freitas se destacó por la "independencia de pensar y pasión por la verdad, que lo extremó entre los juristas de su tiempo". ${ }^{14}$

Irineu Strenger registra este concepto expreso por Hahnemann Guimarães: "En la práctica difícil del celo por la verdad, del amor de la perfección, de la paciencia, de la modestia y de la hontadez, se consumió la vida de Teixeira de Freitas. Las teorías y los códigos envejecen, pero ha de ser siempre nueva en la memoria de los hombres, la imagen de que dedicó a su obra tanta virrud". 15

Cuanto a la importancia de los estudios de Teixeira de Freitas para el Derecho Internacional Privado, se sirve, una vez más, del juicio de Hatoldo Valladão, ya trascrito en otra ocasión: "Freitas propuso, con método admirable, las cuestiones de los conflictos de leyes, quiera en el espacio, quiera en el tiempo, en un sistema nuevo, inspirado en la teoría de Savigny, pero modificado y perfeccionado con varias ideas propias. Lanzaba los principios básicos en un Título Preliminar con que abtía el 'Esbozo' y sus corolarios, sus aplicaciones consolidaba en la Parte Especial junto a cada institución" ${ }^{16}$

13 SLLVA ALONSO, R. Op. cit., p. 153.

"4 PONTES DE MORANDA. Tratado de direito privado, t. IV, p. $243.4^{2}$ ed. São Paulo: Revista dos Tribunais, 1983.

${ }^{15}$ STRENGER, Irineu. Direito internacional privado, v. 1, p. 215. $2^{2}$ ed. São Paulo: Revista dos Tribunais, 1991.

"DEL'OLMO, F.S. Op. cit., p. 12. 
Se vive tiempos de integración. El Mercosur se consolida. Más de diez años se pasaton desde el Tratado de Asunción y los frutos son muy buenos e preemisores. Las batreras, y son muchas, que impiden todavía una aproximación entre los pueblos hermanos de Argentina, Brasil, Paraguay y Uruguay, ya son bien menores que los factores que los impelen en la búsqueda de la identidad regional. Augusto Teixeira de Freitas, el jurista de los cuatro países del bloque, el eslabón identificador entre ellos en la codificación civil en el siglo XIX, bien puede ser recordado como un pertinente emblema de esa búsqueda. Hasta porque él fue, sin sofismas, el protojurista del Mercosur. Quien sabe, en porvenir no tan lejos, así como se conoce el Código Napoleón (de Francia, 1804) y el Código Seabra (de Portugal, 1867), el Mercosur tendrá el Código Teixeira de Freitas. Y será un código único, un código general, dando razón a un científico del Derecho que previó, con más de un siglo de antecedencia, las notables ventajas para el ser humano en disponer de un estatuto en el cual fuesen reguladas todas las relaciones privadas, civiles, comerciales, industriales y laborales. Teixeira de Freitas no estaba adelantado: apenas el mundo tardó cien años para vivenciar lo que su inteligencia privilegiada y su petcuciente estudio entonces habian propuesto. 